\title{
浅论 PPP 模式下公路工程造价的控制与管理
}

\section{Discussion on the Control and Management of Highway Engineering Cost Under PPP Mode 马文霞}

Wenxia Ma

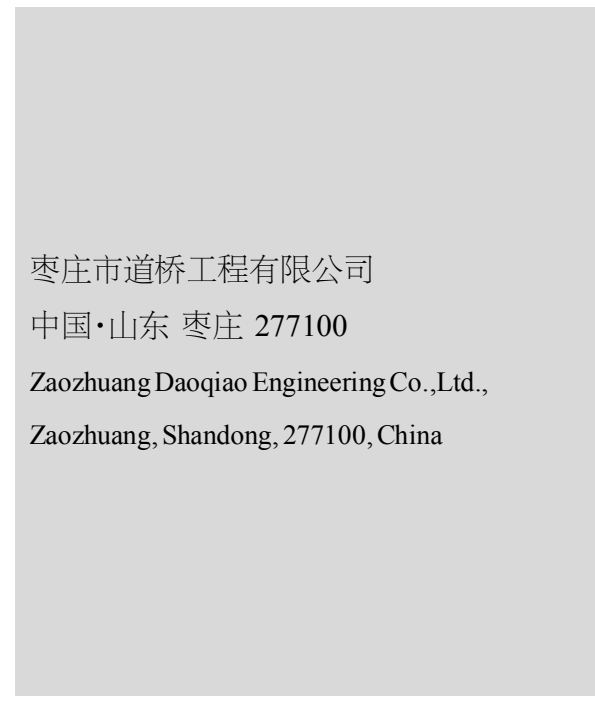

【摘要】公路建设往往是一个国家综合实力发展的命脉,决定贸易的往来和人们出行的 便利性。随着公路建设发展的加快, 其工程造价的控制与管理成为十分重要的把控环节。 论文就目前在 PPP 模式下公路工程单位对于造价控制各个阶段中存在的问题进行分析, 并给出解决方案。

【Abstract】Highway construction is often the lifeblood of the development of a country's comprehensive strength, which determines the trade exchanges and the convenience of people's travel. With the accelerated development of highway construction, the control and management of its engineering cost has become a very important control link. In this paper, the problems existing in each stage of cost control in highway engineering units under PPP mode are analyzed, and the solutions are given.

【关键词】模式; 公路工程造价; 控制与管理

【Keywords \mode; highway engineering cost; control and management

[DOI]10.36012/etr.v1i4.698

\section{1 引言}

传统的工程造价控制管理工作只涉及相应的审批部门, 责任人也有固定的模式来进行造价控制。而 PPP 模式不同于 以往, 这种模式运作时牵扯到更多种类的单位, 甚至包括施工 单位和设计单位, 从整体上进行规划, 从而进行工程造价的合 理协调控制。这就需要各部门通力合作、共同努力,保证工程 的质量, 保证公路建设的顺利实施, 直接促进中国交通行业的 平稳进步。

\section{PPP 模式下工程造价存在的问题}

PPP 模式, 通俗地讲就是公私合营模式, 是指公共机构与 民营机构通过协议形成合作伙伴关系,共同或委托投资建设、 运营、建设管理基础设施项目 ${ }^{[1]}$,与传统管理模式下有很大甚 至本质上的不同。而这种模式在工程造价控制工作中牵扯多 种类的部门,因此,相关部门需要严格的规划管理, 以保证控 制工作的合理进行。

\section{1 工程开始前存在的问题}

公路的建设质量决定经济发展的速度, 建造时的项目通常 是十分宏大的, 因此, 在工程的编排上需要进行宏观调控 ${ }^{[2]} 。$ 传 统的工程造价控制是建立在政府审批的基础上，分析项目的 概况, 结合施工单位的意见进行施工安排, 规划出初步的建造
方案。而对于PPP 模式下的工程造价控制, 则需要考虑各部门 的协调, 并且其最终目的更看重工程在市场上的价值, 通常进 行效益可行性分析。分析的内容通常包括各类风险和交通要 道的未来发展状况, 若是道路将来出现调整, 则需及时更改建 造计划,避免造成损失。

因此,传统模式和 PPP 模式的优劣显而易见, 以往的工 程造价控制更多关注的是工程建造的具体内容和施工质量, 而 PPP 的合作模式则在此基础上加入了对未来市场的规划 和道路发展的变化研究, 将潜在的风险及时规避, 从而创造出 更高的经济效益。但目前真正能够做到符合 PPP 模式要求的 成果较少,还有一定的发展进步空间。

\section{2 工程建造方案没有合理规划}

以往的工程项目没有进行合理的规划，并不能完全做到 甲方提出的要求, 在实施建造时经常会出现概念上的错误, 有 时还会加重预算，过量的建造也往往不能满足投资方真正的 要求。而 PPP 模式也缺少严格的控制措施, 需要提前进行调 研,将建设方案科学合理地编排,细化到具体的施工用材和地 点, 不仅要满足审批、国家宏观调控的要求和防止公共利益受 损,还要满足投资者投资及风险控制的要求。

\section{3 工程造价编制依据}

PPP 模式下,工程造价属于大众水平, 符合市场的标准。 
工程管理 Engineering Management

然而, 定额下的平均先进水平有一定的滞后性, 一到五年不 等,这就造成用定额和标准规划出的常规项目价格偏高, 而定 额中不具有的先进施工技巧、新工艺的造价和实施阶段差距 明显。PPP 模式往往是经过详细的市场调研之后, 进行价格编 排, 有时甲方的意见也是决定工程走向的关键因素, 同样影响 造价的编制。同时, 部分成熟工艺按定额编制造价可能会造成 投资者收益高,使公共利益受损,降低公众满意度。

\section{4 项目设计阶段}

以往的项目设计工作，通常只考虑施工工艺和建造地点 的日期编排,没有考虑到道路后续的发展。然而,在公路工程 中道路的状况很容易发生改变, 比如, 政府的某一规划要对道 路进行拓展或架设桥梁等工作，都会让公路工程的施工质量 受损,工程造价便失去控制,造成不必要的经济损失。同时,在 PPP 模式下,还存在政府调整规划、补贴不到位、政府承诺不 能履行、市场融资环境变化等问题影响项目造价,使项目无法 顺利完成, 不仅对施工单位造成损失,也对社会发展带来阻碍。

\section{5 项目运营和结算阶段}

针对此阶段, 国家也没有相应的手段来支持, 缺乏相关的 管理条例, 没有严格的监督管理措施, 导致公路施工存在一定 的安全隐患。最常见的例子就是竣工时的合同结算问题, 更是 有投资方为多得利益多算成本、发包时“阴阳合同”、政府不认 可结算造价等状况发生,使得公路工程结算存在矛盾,工程造 价难以确认。另外, 还有很多项目不进行后评价, 即使进行后 评价也只注重社会效益和施工方案、技术, 很少考虑资金的时 间价值和项目成本与经济效益。

\section{PPP 模式下加强公路工程造价控制与} 管理的建议

\section{1 培养创新发展的意识}

新时代的发展速度变得越来越快, 无论是管理者还是施 工从业人员都要及时创新自己的意识, 结合最新的建造工艺, 创立新型公路建造模式。

在 PPP 模式下, 政府要转变合作关系, 从系统的调控者 变成投资者, 与施工单位共同承担风险和利益。在这种 PPP 模式下,政府和公路建设单位拟定合同, 形成相关的产业链, 并且此条款不仅能够实现政府实行公路工程造价的合理控 制，也同样保障了政府获得合法收益的权力，属于双赢的措 施。为此, 政府要转变工作职能, 除开单一的造价控制工作 外, 要积极主动地去管理, 同时, 借助合约的约束, 保证造价规 划调整的公开性, 更加积极主动做好造价市场管理工作。
咨询单位在 PPP 模式下也要作出相应的改变, 咨询人员 要紧跟时事, 了解社会的需求, 改变以往咨询的 “走过场”形 式, 真正发挥出自身部门的作用, 让公路工程的投资者们能够 认识到当下的投资形式, 准确地把握机会, 创收更良好的经济 效益。

\section{2 设计阶段要协调进行}

公路工程立项后, 其最核心的阶段就是设计阶段, 良好的 设计能够让工程造价极大地节省, 建造的公路质量也更加科 学, 能够长期使用, 符合社会发展的需要。因此, 施工单位可以 采用 PPP 模式,保证公路工程的建造效益。

在公路工程进行施工的前期阶段, 公路工程的项目设计 人员对于公路项目的各个环节要做好衔接, 对于项目的可行 性报告、设计的任务要求等都要有详细的了解, 对于公路工程 项目沿线的地形地质条件要进行实地考察，从整体上把握公 路工程的建造环境, 确定合理的公路施工技术和流程设计图, 对于存在的临时性状况也要充分考虑, 留有足够的余地, 为公 路工程造价提供全面的参考依据。

\section{3 施工过程中严格按照设计方案进行}

材料的选用不能超过预期的规格, 不能使用设计外的建 筑材料, 同时, 对于施工用的器械要提前备好, 像搅拌机、压路 机等大型机车要合理摆放, 不能影响他人的正常生活。与此同 时, 在施工过程中还要考虑合理性, 不仅要协调安排施工进 度, 还要保证建造质量, 在此基础上进行规划, 尽量降低建造 成本。

对于工程施工, 不能过分注重施工进度、减少成本而忽视 公路质量, 要在保证公路工期质量、工期的同时, 降低施工造 价成本。重视资金的时间价值, 计算各种融资条件下社会融资 成本, 做到真正意义上的全过程动态管理。

\section{4 结语}

基于 PPP 模式的公路工程造价的控制是从整体出发考 虑的一种措施, 其最终保障的还是企业和国家的发展效益。因 此, 做好工程的造价控制与管理是非常重要的, 不仅有利于保 障企业的经济效益, 还有利于促进中国综合实力的提升, 具有 长远的发展空间和广阔的前景。

\section{参考文献}

[1]王刚.浅析 PPP 模式下公路工程造价的控制与管理[J].建材与 装饰,2016(17):220-221.

[2]宋中秋.PPP 模式下公路工程造价的控制与管理[J].交通世界, 2017(30):149-150 